\section{CRISPR gene therapy trial on hold}

The US Food and Drug administration has delayed the start of a human study of a genetically engineered therapy for treating sickle cell disease. In May, the agency issued a clinical hold on the investigational new drug application filed by Vertex and CRISPR Therapeutics to test CTX001, a new autologous gene therapy made with CRISPR-Cas9 technology, pending resolution of questions from the agency. No other details on the reason for this hold were disclosed. CTX001 is designed to produce high levels of fetal hemoglobin $(\mathrm{HbF})$ in red blood cells. $\mathrm{HbF}$ is a form of the oxygen-carrying hemoglobin that is naturally present at birth, and is then replaced by the adult form of hemoglobin. The hope is that elevating $\mathrm{HbF}$ using CTX001 can alleviate transfusion requirements and debilitating crises for sickle cell and $\beta$-thalassemia patients. In December 2017, CRISPR presented preclinical data showing greater than $90 \%$ editing of hematopoietic stem cells at the target site, leading to clinically relevant increases in $\mathrm{HbF}$. According to CRISPR Therapeutics, which is headquartered in Zug, Switzerland, a European trial of CTX001 in patients with transfusion-dependent $\beta$-thalassemia remains on track to begin later this year. The company's collaborator Vertex has also exercised an option to co-develop CTXO01 for hemoglobinopathies. In February 2018, the University of Pennsylvania in Philadelphia began enrolling patients in the first CRISPR trial in the US, to treat multiple myeloma, melanoma and sarcoma, using engineered autologous NY-ESO-1 T cells, edited to remove endogenous TCR and PD-1. Several trials of cells engineered using CRISPR-Cas9 technology are recruiting in China.

\section{6 "Anyone who does synthetic biology should be under surveillance, and anyone who does it without a license should be suspect." Harvard University geneticist George Church comments on the publication of an experiment recreating a virus that has engendered fears that such information could be used to create a bioweapon. (The New York Times, 14 May 2018)}

\footnotetext{
"When you put DNA and privacy together in a sentence, understandably and correctly, it makes people nervous." Laura Hercher, of Sarah Lawrence College, comments on the recent security breach at MyHeritage.com, in which e-mails and passwords belonging to over 92 million site users were leaked. She added "I would rather give someone my DNA than my social security number, my search history, or my credit card." (STAT, 5 June 2018)
}

their eye diseases. The initial study is designed to assess how well it works when patients measure their own visual acuity and contrast sensitivity.

Science 37's largest trial to date is an ongoing phase 4 diabetes study with Sanofi enrolling only African-American, Asian and Hispanic patients in the US. The tech company is tracking responses to Sanofi's Admelog, an insulin lispro, which is a rapid-acting insulin analog first developed by Eli Lilly and sold as Humalog. Admelog received FDA approval in December after being fast-tracked as a followon to Humalog. Overall, Science 37 has had about $40 \%$ minority participation in its trials, says Craft. Minorities make up 39\% of the US population, according to the US Census Bureau.

Sanofi has yet to run a trial that is fully virtual. So far, the big pharma has run trials half with Science 37's platform and the other half through traditional clinical sites, says Lionel Bascles, Sanofi's global head of clinical sciences and operations.

In addition to providing companies with participants' data from real-life
"We basically can't scale fast enough to do all the trials people want us to do." done on-site or through a contracted lab, and the remainder of the trial conducted at home. The hybrid approach can still provide most of the convenience of virtual clinical trials, says Novartis' Bodson.

Software-powered trials will apply to a broad array of indications. UCB, based in Brussels, plans to focus first on neurology and immunology; Basel-based Novartis, which announced its partnership with Science 37 in March, is planning trials in dermatology, neuroscience and oncology. Otsuka, headquartered in Tokyo, inked its deal with the company in December, and plans to run trials in psychiatry and behavioral health. Paris-based Sanofi, which has had a partnership with Science 37 since March 2017, will run trials in chronic obstructive pulmonary disease among other indications.

Though Science 37 has attracted some big names, it's not the only game in town for virtual clinical trials. Contract research organizations Center Point Clinical Services, and Clinpal of Stirling, Scotland, offer siteless clinical trial services. All of Center Point's clinical trisettings, virtual clinical trials promise access to greater amounts of data than is possible in the traditional clinical trial model, says Bascles. Instead of collecting data once a month, or, when patients come into trial centers, virtual trials will collect data more frequently, and potentially continuously from home, without burdening the patient, he says.

Beyond patients completing quality-oflife surveys and recording other qualitative observations, home data collection can include measurements from smartphone- and computer-connected sensors. For instance, Science 37 has validated iPhone cameras as a means of collecting data on acne, says Craft. Science 37 is also in discussions with a company to use its 12-lead electrocardiogram system. Several 12-lead electrocardiogram systems have received FDA approval for home use. Also, Science 37's partners are working with the company to develop new digital biomarkers, says Craft.

There will always be some tests and procedures, such as MRIs and biopsies that have to happen in hospitals or other traditional clinical sites. In such cases, studies can run as hybrid trials, with the tests and procedures als are site-less; and it has run eight so far, the first in 2015, according to CEO Gerald Finken. Also, other pharma have experimented with social-media- and app-based recruitment and digital biomarkers, as well. Roche and GlaxoSmithKline, for example, have used the Apple ResearchKit in clinical trials (Nat. Biotechnol. 33, 1013-1014, 2015).

Virtual clinical trials may take some time to prove their worth. Nonetheless, Ashish Atreja, chief innovation officer, medicine, at the Icahn School of Medicine at Mount Sinai in New York, expects that site-less and hybrid approaches will become standard for most clinical trials in five to seven years.

The industry appears to be betting that way, too. In three and a half years, Science 37 has grown to 200 employees, half of whom are physicians, and plans to expand internationally by the end of next year, says Craft. "We basically can't scale fast enough to do all the trials people want us to do," he says. The company is encouraging others to adopt its model, and has begun licensing its platform, he says. One major milestone to watch for: the first pivotal virtual clinical trial that leads to regulatory approval.

Eric Smalley Boston 